\title{
Dreams and the daydream retrieval hypothesis
}

\section{Background}

Dreams and daydreams are as beguiling as they are intangible (Barrett, 2018). Both share many features, from neurobiology to the sensed experience. Nevertheless, the specific narrative relationship between both, if any, remains uncertain. Theories of dream origins are many: from the psychodynamic royal road, (Freud, 1913) to biological theories, including Hebbian based memory consolidation (Voss \& Klimke, 2017), and a unified quantum brain theory that extends to waking and dreaming alike (Globus, 2017). Both the ephemeral nature of dreams* and an inability to simultaneously study their content and biology render them difficult to research from a conventional biomedical perspective. This leaves agreement on the fundamental properties of dreams as ambiguous, and even the state of consciousness enjoyed during sleep is contested (Freud, 2013). What is known is that the qualia and neurophysiological signature of dreams and daydreaming share many features (Domhoff, 2011). We propose further, from a subjective experientialist position, that dream content is specifically derived from daydreams or mindful wandering (subserved by the default mode network [DMN]). If substantiated, this concept offers a new insight into the origin of dreams.

*White dreams, where dreams are experienced but not remembered, account for onethird of dream reports (Fazekas, 2018)

Current state of knowledge of daydreamsDaydreaming is a state of stimulus independent mind-wandering that may almost unknowingly occupy much of waking life (Baird et al., 2011, Domhoff, 2011). Humans tend to daydream, or mind wander $30-50 \%$ of the time while awake (Domhoff, 2011). Daydreaming achieves deep processing during off-task thinking with the tangible benefits of creativity conferred, such as mental time travel (Finnbogadottir 2013). Stimulus independent and undirected mind wandering may still be associated with enabling imagination and creativity in the subject (Klinger and Cox, 1987; Beaty et al., 2018; Klinger 1990, Klinger 2009, Kuzendorf et al., 1997). Daydreaming often involves mental simulation of self into a different place, time or realm (Singer, 1966; Markman, 2009). Daydreaming is a notable preoccupation of writers and poets and is understandably associated with the creative type (Singer \& McCraven, 1961). Fantasy, role-play and even metaphor production are among some of the experiences and explorations of the mind during this phase (Beaty et al., 2017). Constructive daydreaming has even been linked with positive life attributes (Blouin-Hudon, 2016). Daydreaming also achieves 'perceptual decoupling to escape the constraints of the moment' and attain internal stream maintenance (Antrobus 1964, Smallwood, 2011). Earlier theories proposed an adaptive role of daydreams to an individual's well-being (Singer, 1966) and suggest a conformity to the psychodynamic framework of wish-fulfillment (Singer \& McCraven, 1961; Singer, 1998). Original psychology studies have now been complemented with neurobiological correlates, courtesy of functional MRI scanning and electrophysiology, which have identified the default mode network as a key hub involved in daydreaming. Mind wandering has been shown to be strongly linked with default mode network activity, midline cerebral hubs, such as the angular gyrus, medial prefrontal cortex (mPFC) and posterior cingulate gyrus (Antrobus, 2016). The dynamic functional connectivity of the DMN is proportionate with an individual's self 
report of mind wandering (Kucyi \& Davis, 2014). Charged emotions can increase the dream-like intensity and symbolism of mind-wandering (Hartmann et al., 2003). Some of these effects can be mimicked by psychedelic agents with ego-disintegration at peak effects associated with loss of salience network integrity (Driesen et al., 2013; Lebedev, 2015). Moreover, the daydreamers may not be just winning as romantics but through enriched recruitment of ancillary networks (the dorsomedial subsystem) they may be maximising their cognitive commitment to distal simulation and becoming in the process creative experts (Meyer, 2019). The default mode co-operates reciprocally as a paired network with the task positive/executive states to generate the fruits of creative contemplation as part of daydreaming to be assimilated later.

\section{Current state of knowledge of dreams}

Hippocampal-dependent learning is accessible during non-REM sleep. This may influence the subjective experience of dreams (Wamsley \& Antrobus, 2009), which are congruent with the dreamers' underlying emotion (Hartshorn, 1977, Hartmann, 2010). Current concerns are known to influence dream content (Gold and Reilly, 1985, Sikka et al., 2018) and this contribution is inflated with pre-sleep reinforcement (Nikles II, 1998). Additionally, a theory of thwarted goal commitment posits that unfulfilled themes can be recycled through mind-wandering or dreaming (Klinger, 2013). The personality of the sensitive soul, with so called thin boundaries, may render a parody of dreams, the experience becoming more 'dream-like, emotional and bizarre.' (Hartmann and Kunzendorf, 2006). Previous work has established that daytime subjective experience is frequently represented in dream content (Freud, 1913; Stickgold et al, 2000; Wamsley \& Stickgold, 2009, Solms, 1997), often events from the preceding day (Freud, 1913)and influences waking affective state (Komasi et al., 2018). Many dreams are highly visual, comprising content such as people, faces, places, objects, and animals (Hobson, 1988). From a neurobiological perspective, there is overlap between sleeping and mind-wandering, with activation of the DMN and decreased activation of the dorsolateral prefrontal cortex (dlPFC; Fox, 2013, Dang-Vu et al, 2010, Domhoff \& Fox, 2015, Tagliazucchi \& van Someren, et al, 2017), an area associated with decision-making and working memory, being common to both states. Indeed, cessation of dreaming has been observed in patients with lesions in dlPFC, leading to the forebrain dream-on hypothesis (Eichenlaub et al., 2014, Ouhaz et al., 2018). At an experiential level, both have a similar quality and daydreams can even seamlessly drift into dreams, resulting in a sense of continuity for the dreamer. But apart from many shared properties, not least the sensed experience or qualia, is there a direct relationship between dreams and daydreams?

\section{Research methodology}

Using a subjective experientialist position to examine both dreams and daydreams provides an opportunity to explore and contrast dreams with daydreams (Yost \& Kalish, 1955). Whilst, admittedly, this is a retrospective, unreliable, and incomplete montage of dreams and daydreams, it can still be fruitful in that it provides the only insight into the subject of either. We used recall diaries to explore the relationship of subject content between dreams and daydreams and identified the representation of dream content from binary states of mind; reflective versus task positive thinking. 
These are preliminary behavioural findings, which could be used explore the understanding of dreams further, using advances in functional imaging and neurophysiology.

\section{Research methodology and findings}

Borrowing from Yost and Kalish (Yost \& Kalish, 1955), the author drew on his own dream content to develop a subjective experientialist position. In relating this to wakeful experience, dream hypotheses were generated, putatively with respect to neurobiology.

A diarised case series of dream content experienced on consecutive days over a oneweek period was recorded. Activities from the previous day were also diarised, together with any associated thoughts and reflections. Potential links were explored from a qualitative perspective between waking activity and dream content. A daydream experience was one in which, according to the dynamic framework, 'thoughts arise and proceed in a relatively free, unconstrained fashion', an example of which is watching the sunset (Christoff et al., 2018). Conversely, a task-positive activity was a goal directed, attentional event (e.g., driving; Eeles et al., 2017, p.123).

Specifically, the recalled dream content included a whale, an invitation to a retirement dinner, and a new office, respectively. Recall of waking events revealed a number of connections to subsequent dream content i.e., reading a newspaper that featured a story about an inflatable whale, viewing a retirement poster of a well-known colleague, and visiting the new office of an academic peer. The associated thoughts with respect to each waking task were generally questions concerning the object or focus of the dream. For example, in relation to an inflatable whale in a newspaper article, the primary though elicited at the time was "what would we possibly do with one of these?' With regard to the retirement invitation, thoughts were primarily 'how has work changed since I met this person? In terms of the new office, the reflective thought was 'what would it be like to be working in one of these rather than in my current mess?'

The self-questioning nature of waking contemplation and the retrospective recall of the experience would suggest a daydreaming (in neurobiology terms 'off-task') state of mind (see table 1).

\section{Interpretation}

The subjective, experientialist reflections provided indicate an association between the respective content of dreams and prior daydreaming. The time-orderliness of experience suggests that the daydream is a sentinel event for subsequent dreaming. Whilst limited in interpretation, by not least the sample size, this not the first study to describe the dream experiences of a single individual to propose new theories of dreaming (Corriere et al., 1977). However, the coincidence of peculiar and uncommon daydream experiences reappearing in a similar guise during subsequent dreams also suggests that such associations should not be dismissed. To this extent, we propose that: (1) the content of mind wandering is retained for secondary processing, and (2) the object of the daydream is woven into a dream story as a predominantly visual representation. We posit that dreams are recycled from mind 
wandering content from the previous days. A review of the neurobiology of mind wandering and dreaming follows.

\section{Neurobiology of dreaming and mind-wandering}

We hypothesize that the DMN generates content during daydreams for secondary processing in dreams. What is known is that there is significant neurobiological convergence between mind wandering and dreaming to the point that in both simulated embodied states, the default mode is preferentially activated (Chow et al., 2013, Fox et al., 2013). It has even been shown that incorporation of a daytime event into the dream state, with regard to computerized tasks, is associated with improvement in those performance-related tasks (Wamsley \& Stickgold, 2018). The question remains, however, as to how daydreams and dreams might directly interrelate in this revised relationship (i.e., the daydream retrieval hypothesis). An additional question pertains to whether or not the dream state introduces the conditions under which daydreams can be retrieved, as the content of mind wandering are frequently eclipsed during sentience (Delaney et al., 2010). There is support for autobiographical memory and self-reflection tasks being a function of the DMN during wakefulness (Cipolli et al., 2017). In addition, much recent evidence has been amassed linking the dynamic functional interaction between the DMN and taskrelated networks to imagination and creative cognition (Beaty et al., 2018; Meyer et al., 2019), production of creative ideas (Beaty et al., 2017), psychedelic experience (Fox et al., 2018), and daydreaming itself (Kucyi \& Davis, 2014). It is, therefore, conceivable that retrieval of events from the DMN is possible during the dreaming state.

Alternatively, candidate memory encoding sites that may be responsible for memory consolidation under DMN thinking include the hippocampus and thalamus (McAvoy et al., 2017). Whilst the hippocampus is critically involved in encoding and retrieval of declarative memories, it does not appear to be active during rapid eye movement (REM) sleep and dreams (Solms, 2013). The daydream-dream network (and any projected network implicated in dreams) is likely to incorporate the secondary visual cortex, which is active during REM sleep (McAvoy et al., 2017) and forms part of the parieto-occipital hot spot (Siclari et al., 2017). The thalamus-limbic circuitry, or thalamocortical loop, is also known to be active during REM sleep and is a candidate system for daydream-dream anterograde memory processing (Guo et al., 2017). The thalamus is involved in sleep wake control (Gent et al., 2018) and is rhythmically anticorrelated with the DMN during REM sleep (Siclari et al., 2017). Perhaps this oscillating dominance represents an alternating narrative derived from daydreaming and generated through the thalamocortical loop and made sense of within the dream sequence through higher-level circuitries, such as the DMN (Chow et al., 2013)?

\section{Evidence from elsewhere}

Daydreaming about loved ones is known to positively influence the state of waking happiness (Mar et al, 2012). It is entirely possible that it is the recycling of positive daydream content during dreaming that may reinforce this state of being. There is evidence to suggest that activities conducive to mind-wandering are favoured as 
dream content, walking, talking and, unsurprisingly, sexual activity (Hartmann, 2000). Further, there is a direct correlation between fantasy immersion and the phenomenal qualities of dreams (Levin \& Young, 2002). As such, if the DMN is cardinal source of dream content then its functional antonym, the task positive state and activities associated with its activation, should be excluded from contribution to the dreamer's tableau. Indeed, this would seem to be so, as activities associated with task positive cognition, such as reading, writing, and typing occur very infrequently in dreams (Hartmann, 2000). From an earlier position that fantasy and dreams are part of an experiential continuum, it is known that their neurobiological origins are also shared. What we argue is that rather than behaving in isolation, daydreams directly inform dream content. It would be reasonable to assert that the case for default mode network activity being a progenitor to dreams is supported by empirical data and overwhelming logic but has yet to have been quite articulated to this effect. As one might expect, visual manifestation of dreams diminish in late life blindness which does nothing to contradict the visual integration of dreams from daydreams if there are no visual cues during this time (Meaidi et al., 2014). Conflictingly, there is some evidence that the pathways involved in REM dreaming are less imagination related and more perception specific which runs counter to our daydream retrieval hypothesis (LaBerge et al., 2018).

\section{Summary thus far:}

- Dreams remain a highly unexplored dimension of human life relative to health and disease;

- There is support for the concept of dream content being derived directly from preceding daydream content;

- A subjective experiential perspective may be the most feasible method of examining dream content and its link to daydreams;

- The DMN or thalamocortical loop may be candidate neurobiological circuitries for memory passed down in the dream sequence and generated by the visual cortex.

\section{How can this hypothesis be tested?}

It is difficult to verify in waking life the state of engagement with respect to 'on' and 'off' tasks. The only definitive way of confirming this is through functional MRI where the default mode condition can be correlated with an off-task state and vice versa. An incremental methodology is proposed that integrates multidimensional assessments of sleep and state of waking mind.

\section{Part 1a: Dream recall.}

A number of images can be configured for both on-task and off task during fMRI. The images should be selected at random with no duplication. A sleep diary should be kept by the participants. The relationship between the prevalence of images reappearing in the dream state, as assessed by an independent rater, would be compared with the functional paradigm (on- or off-task).

\section{Part 1b Enriched dream recall.}


Participants could be presented with repeat displays of the images (and additional novel images) with a question, 'yes or no, do you recall dreaming of this item the previous evening?'

\section{Part 1c Challenged dream recall.}

The fMRI, dream diary, dream recall series would be repeated under on-task conditions.

\section{Part 2 Virtual assessment}

Exploration of the dream sequence could occur using the neurophysiological signature of dreams and sleep against artificial intelligence (AI). This could be operationalised by examining participants undergoing MRI whilst simultaneously monitoring DMN and recording the EEG. From this, an EEG marker of DMN in daydream mode can be established. Using this data, an AI can be used to detect subtle changes from nonday dreaming EEG states (Zappasodi et al, 2019). Dream states, using EEG, can then be used to discriminate DMN versus task positive states via EEG. Subsequently, participants could be monitored with an ambulatory EEG for 24 hours with an event diary to recall their activities and thought content during the day. Detailed thought content and the various triggers eliciting the thoughts should be recorded (perhaps at the end of the day). The following day, participants should complete a dream diary, and the ambulatory EEG data should be reviewed. Inference of daydreaming state can then be made in relation to dream/daydream events to explore for associations.

\section{What would be the benefit of dream/daydream derivation?}

There may be several reasons why daydreams might provide content to the dream state. Dreams offer a second chance to explore the boundaries of possibility, or as Sigmund Freud declared 'wish-fulfilment that is created during reflective wakeful thinking.' The influential threat simulation theory (Malcom-Smith et al., 2012) also proposes that reward and fear conditioning, and safe rehearsal of these events, is common during dreaming.

If reflective thinking is a definitive adaptation in humans, as the structures affiliated with the default mode network, such as the precuneus, and their evolutionary expansion would suggest (Bruner et al., 2017), then it may also signal the hierarchal importance of this thinking beyond the competing immediacy of the hunter gatherer predicament (more of a task-positive state of attention (Eeles, 2017). Revisiting this unique default mode function during dreaming might confer certain advantages by exploring the space of opportunity with respect to situational concerns that comes free from physical risk and consequence. Ultimately, the daydream retrieval hypothesis is testable. If confirmed, dreams may still be devoid of reason (Dostorevsky, 1864) but we may be in a position to blame our daydreams.

\section{References}

Antrobus, J., \& Singer, J. L. (1964). Eye movements accompanying daydreaming, visual imagery, and thought suppression. Journal of Abnormal and Social Psychology, 
69, 244-252.

Antrobus, J. (2016). What Waking Perception and Mindwandering Might Tell Us About How the Frontal and Prefrontal Cortices Enable Dream and Daydream Images and Thought. (Unpublished Paper), City University of New York, New York.

Baird, B., Smallwood, J., Schooler, J.W. (2011). Back to the future: autobiographical planning and the functionality of mind-wandering. Conscious Cogn. 2011 Dec;20(4):1604-11. doi: 10.1016/j.concog.2011.08.007. Epub 2011 Sep 13.

Barrett, D. (2018). Dreams and creative problem-solving. Archives Italiennes de Biologie, 1;156(3):99-111. doi: 10.12871/00039829201832.

Beaty, R., Chen, Q., Qiu, J., Silvia, P., \& Schacter, D. (2018). Brain networks of the imaginative mind: Dynamic functional connectivity of default and cognitive control networks relates to openness to experience. Human Brain Mapping, 39, 811-821.

Beaty, R., Silvia, P. J., \& Benedek, M. (2017). Brain networks underlying novel metaphor production. Brain and Cognition, 111(163-170).

Blouin-Hudon EC, Zelenski JM. (2016). The daydreamer: Exploring the personality underpinnings of daydreaming styles and their implications for well-being. Conscious Cogn;44:114-129. doi: 10.1016/j.concog.2016.07.007. Epub 2016 Jul 29.

Bruner, E., Preuss, T.M, Chen, X., \& Rilling, J.K. (2017). Evidence for expansion of the precuneus in human evolution. Brain Structure and Function,222(2):1053-1060. doi: 10.1007/s00429-015-1172-y. Epub 2016 Jan 2.

Chow, H.M., Horovitz, S.G, Carr, W.S.,Picchioni, D, Coddington, N., Fukunaga, M., Xu, Y., Balkin, T.J., Duyn, J.H., \& Braun, A.R. (2013). Rhythmic alternating patterns of brain activity distinguish rapid eye movement sleep from other states of consciousness. Proceedings of the National Academy of Sciences of the US A, 110(25): 10300-10305. doi: 10.1073/pnas.1217691110

Christoff, K., Mills, C,, Andrews-Hanna, J.R., Irving, Z.C., Thompson, E., Fox, K.C.R. \& Kam, J.W.Y. (2018) Mind-Wandering as a Scientific Concept: Cutting through the Definitional Haze. Trends in Cognitive Science, 22(11):957-959. doi: 10.1016/j.tics.2018.07.004. Epub 2018 Sep 13.

Cipolli, C., Ferrara, M., De Gennaro, L., Plazzi, G. (2017). Beyond the neuropsychology of dreaming: Insights into the neural basis of dreaming with new techniques of sleep recording and analysis. Sleep Med Rev, 35:8-20. doi: 10.1016/j.smrv.2016.07.005. Epub 2016 Jul 28.

Corriere R, Hart J, Karle W, Binder J, Gold S, Woldenberg L. (1977). Toward a new theory of dreaming. J Clin Psychol;33(3):807-20. 
Dang-Vu, T.T., Schabus, M., Desseilles, M., Sterpenich, V., Bonjean, M. \& Maquet, P.(2010). Functional Neuroimaging Insights into the Physiology of Human Sleep.

Sleep. 33(12): 1589-1603.

Delaney, P.F., Sahakyan, L., Kelley, C.M., \& Zimmerman, C.A. (2010).

Remembering to forget: the amnesic effect of daydreaming. Psychological Science, 21(7):1036-42. doi: 10.1177/0956797610374739. Epub 2010 Jun 14.

Domhoff, W.G. (2011). Conscious The neural substrate for dreaming: is it a subsystem of the default network? Cognition. 20(4):1163-74. doi:

10.1016/j.concog.2011.03.001. Epub 2011 Mar 29.

Domhoff, W. G. \& Fox, K.C. (2015). Dreaming and the default network: A review, synthesis, and counterintuitive research proposal. Consciousness and Cognition, 33:342-53. doi: 10.1016/j.concog.2015.01.019. Epub 2015 Feb 24. Review.

Dostoevsky, F. (1864). Notes from Underground. Epoch.

Driesen, N.R.,McCarthy, G.,Bhagwagar, Z., (2013). Relationshipof resting brain hyperconnectivity and schizophrenia--- like symptoms produced by the NMDA receptor antagonist ketamine in humans. Molecular psychiatry, 18(11),1199--- 1204.

Eeles, E., Burianova, H., Pandy, S. \& Pinsker, D. (2017). Consciousness, Functional Networks and Delirium Screening. Current Aging Science, 10(2):122-128. doi:10.2174/1874609809666161004142027. Review.

Eichenlaub, J.B., Nicolas, A., Daltrozzo, J., Redouté, J., Costes, N. \& Ruby, P. (2014). Resting brain activity varies with dream recall frequency between subjects. Neuropsychopharmacology, 39(7):1594-602. doi: 10.1038/npp.2014.6. Epub 2014 Jan 16.

Fazekas, P., Nemeth, G. \& Overgaard, M. (2018). White dreams are made of colours: What studying contentless dreams can teach about the neural basis of dreaming and conscious experiences. Sleep Medicine Reviews, 43:84-91. doi:

10.1016/j.smrv.2018.10.005. [Epub ahead of print]

Finnbogadóttir., H. \& Berntsen, D. Involuntary future projections are as frequent as involuntary memories, but more positive. Consciousness and Cognition. 2013 Mar;22(1):272-80. doi: 10.1016/j.concog.2012.06.014. Epub 2012 Aug 9.

Fox, K.C., Nijeboer, S., Solomonova, E., Domhoff, G.W. \& Christoff, K. (2013) Dreaming as mind wandering: evidence from functional neuroimaging and firstperson content reports. Frontiers in Human Neuroscience 7:412. doi: 10.3389/fnhum.2013.00412. eCollection 2013.

Freud, S. (1913). The interpretation of dreams. New York: Macmillan. 
Gent, T.C., Bassetti, C. \& Adamantidis, A.R.(2018) Sleep-wake control and the thalamus. Current Opinion in Neurobiology, 52:188-197. doi:

10.1016/j.conb.2018.08.002. Epub 2018 Aug 23.

Globus, G. (2017). Quantum brain theory and the appearing of world.

Journal of Integrative Neuroscience; 16(s1):S37-S42. doi: 10.3233/JIN-170065.

Gold, S., \& Reilly, J. (1985/1986). Daydreaming, current concerns, and personality. Imagination, Cognition and Personality, 5, 117-125.

Guo, Z.V., Inagaki, H.K., Daie, K., Druckmann, S., Gerfen, C.R. \& Svoboda, K. (2017). Maintenance of persistent activity in a frontal thalamocortical loop..Nature, 545(7653):181-186. doi: 10.1038/nature22324. Epub 2017 May 3.

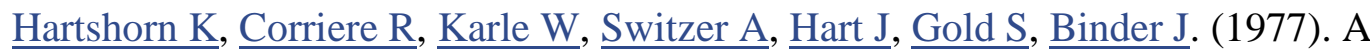
reapplication of the process scoring system for dreams. J Clin Psychol;33(3):844-8.

Hartmann E. We Do Not Dream of the 3 R's: Implications for the Nature of Dreaming Mentation Dreaming. June 2000, Volume 10, Issue 2, pp 103-110

Hartmann, E., Kunzendorf, R. G., Baddour, A., Chapwick, M., Eddins, M., Krueger, C.,Shannon, R. (2002-2003). Emotion makes daydreams more dreamlike, more symbolic. Imagination, Cognition \& Personality; 22, 255-274.

Hartmann E. 2010)The underlying emotion and the dream relating dream imagery to the dreamer's underlying emotion can help elucidate the nature of dreaming. Int Rev Neurobiol. 2010;92:197-214. doi: 10.1016/S0074-7742(10)92010-2.

Hobson JA. The Dreaming Brain. Basic Books; 1988.

Klinger, E., \& Cox, W. (1987-1988). Dimensions of thought flow in everyday life. Imagination, Cognition, and Personality, 7, 105-128.

Klinger, E. (1990). Daydreaming. Los Angeles: Jeremy P. Tarcher.

Klinger, E. (2009). Daydreaming and fantasizing: Thought flow and motivation. In K. Markman, W. Klein, \& J. Suhr (Eds.), Handbook of imagination and mental simulation (pp. 225-239). New York: Psychology Press.

Klinger E. (2013). Goal Commitments and the content of thoughts and dreams: basic principles. Front Psychol. 2013 Jul 11;4:415. doi: 10.3389/fpsyg.2013.00415. eCollection. 
Komasi, S., Soroush, A., Khazaie, H., Zakiei, A. \& Saeidi, M. (2018). Dreams content and emotional load in cardiac rehabilitation patients and their relation to anxiety and depression..Annals of Cardiac Anaesthesia, 21(4):388-392. doi: 10.4103/aca.ACA_210_17.

Kucyi, A., \& Davis, K. D. (2014). Dynamic functional connectivity of the default mode network tracks daydreaming. Neuroimage, 100, 471-480.

Kunzendorf, R. G., Hartmann, E., Cohen, R., \& Cutler, J. (1997). Bizarreness of the dreams and daydreams reported by individuals with thin and thick boundaries.

Dreaming; 7, 265-271.

LaBerge, S., Baird, B. \& Zimbardo, P.G. (2018). Smooth tracking of visual targets distinguishes lucid REM sleep dreaming and waking perception from

imagination..Nature Communications, 9(1):3298. doi: 10.1038/s41467-018-05547-0.

Lebedev,A.V.,Lovden,M.,Rosenthal,G.,Feilding,A.,Nutt,D.J.,\&Carhart- Harris,R.L.( 2015). Finding the self by losing the self: Neural correlates

Of ego- dissolution under psilocybin. Human Brain Mapping;36(8):3137-53.

Levin, R., \& Young, H. (2001-2002). The relation of waking fantasy to dreaming. Imagination, Cognition \& Personality, 21, 201-219.

Malcolm-Smith, S., Koopowitz, S., Pantelis, E., Solms, M. (2012).

Approach/avoidance in dreams. Consciousness and Cognition, 21(1):408-12. doi:

10.1016/j.concog.2011.11.004. Epub 2011 Dec 22.

Mar RA, Mason MF, Litvack A. (2012). How daydreaming relates to life satisfaction, loneliness, and social support: the importance of gender and daydream content.

Conscious Cogn;21(1):401-7. doi: 10.1016/j.concog.2011.08.001. Epub 2011 Oct 26.

Markman, W. Klein, \& J. Suhr (Eds.), Handbook of imagination and mental simulation (pp. 225-239). New York: Psychology Press.

McAvoy, M., Mitra, A., Tagliazucchi, E., Laufs. H., \& Raichle. M.E. (2017).

Mapping visual dominance in human sleep. Neuroimage, 150:250-261. doi:

10.1016/j.neuroimage.2017.02.053. Epub 2017 Feb 21.

Meaidi, A., Jennum, P., Ptito, M. \& Kupers, R. (2014). The sensory construction of dreams and nightmare frequency in congenitally blind and late blind individuals.

Sleep Medicine, 15(5):586-95. doi: 10.1016/j.sleep.2013.12.008. Epub 2014 Feb 18.

Meyer, M. L., Hershfield, H. E., Waytz, A. G., Mildner, J. N., \& Tamir, D. I. (2019).

Creative expertise is associated with transcending the here and now. Journal of

Personality and Social Psychology, 116, 483-494. doi:DOI:10.1037/pspa0000148 
Nikles CD 2nd, Brecht DL, Klinger E, Bursell AL. (1998). The effects of currentconcern- and nonconcern-related waking suggestions on nocturnal dream content $\mathrm{J}$ Pers Soc Psychol.;75(1):242-55.

Ouhaz, Z., Fleming, H. \& Mitchell, A.S. (2018). Cognitive Functions and Neurodevelopmental Disorders Involving the Prefrontal Cortex and Mediodorsal Thalamus. Frontiers in Neuroscience, 12:33. doi: 10.3389/fnins.2018.00033. eCollection 2018.

Siclari, F., Baird, B., Perogamvros, L., Bernardi, G., LaRocque, J.J., Riedner, B., Boly, M., Postle, B.R. \& Tononi, G.. (2017). The neural correlates of dreaming. Nature Neuroscience, 20(6): 872-878. doi: 10.1038/nn.4545

Sikka, P., Pesonen, H. \& Revonsuo, A. (2018). Peace of mind and anxiety in the waking state are related to the affective content of dreams. Scientific Report, 8(1):12762. doi: 10.1038/s41598-018-30721-1.

Singer, J. L., \& McCraven, V. G. (1961). Some characteristics of adult daydreaming. The Journal of Psychology, 51, 151-164. doi:DOI:10.1080/00223980.1961.9916467

Singer, J. L. (1966). Daydreaming. New York: Random House.

Singer, J. L. (1998). Daydreams, the stream of consciousness, and self-representations. In R. Bornstein \& J. Masling (Eds.), Empirical Perspectives on the psychoanalytic unconscious. Washington: American Psychological Association Press.

Solms, M. (1997). The neuropsychology of dreams: A clinico-anatomical study. Hillsdale, NJ: Erlbaum.

Solms, M. (2013). Dreaming is not controlled by hippocampal mechanisms.

Behavioural Brain Science, 36(6):629; discussion 634-59. doi: 10.1017/S0140525X1300143X.

Smallwood, J., Schooler, J.W., Turk, D.J., Cunningham, S.J., Burns, .P, Macrae, C.N. (2011). Self-reflection and the temporal focus of the wandering mind.

Consciousness and Cognition, 20(4):1120-6. doi: 10.1016/j.concog.2010.12.017. Epub 2011 Jan 31.

Stickgold, R., Malia, A., Maguire, D., Roddenberry, D., \& O'Connor, M. (2000). Replaying the game: Hypnagogic images in normals and amnesics. Science, 290, 350-353

Tagliazucchi, E. \& van Someren, E.J.W. (2017). The large-scale functional connectivity correlates of consciousness and arousal during the healthy and pathological human sleep cycle. Neuroimage 160:55-72. doi:

10.1016/j.neuroimage.2017.06.026. Epub 2017 Jun 12. 
Voss, U. \& Klimke, A. (2017). Dreaming during REM sleep: autobiographically meaningful or a simple reflection of a Hebbian-based memory consolidation process? Annals of the New York Academy of Sciences, 1406(1):64-67. doi:

10.1111/nyas.13412. Epub 2017 Jun 22.

Wamsley, E. J. \& Stickgold, R. (2009). Incorporation of waking events into dreams. The neuroscience of sleep (pp. 330-336). London, UK: Academic Press.

Wamsley EJ, Antrobus JS. (2009). The expression of trace conditioning during nonREM sleep and its relation to subjective experience. Neurobiol Learn Mem;92(3):28391. doi: 10.1016/j.nlm.2009.02.012. Epub 2009 Feb 28.

Wamsley E. J, \& Stickgold, R. (2018). Dreaming of a learning task is associated with enhanced memory consolidation: Replication in an overnight sleep study. Journal of Sleep Research, e12749. doi: 10.1111/jsr.12749. [Epub ahead of print]

Yost, R.M. \& Kalish, D. (1955). Miss MacDonald on Sleeping and Waking. Philosophical Quarterly, 5(19):109-124(1955).

Zappasodi, F., Perrucci, M.G., Saggino, A., Croce, P., Mercuri, P., Romanelli, R., Colom, R. \& Ebisch, S.J.H. (2019). EEG microstates distinguish between cognitive components of fluid reasoning. Neuroimage, 189:560-573. doi:

10.1016/j.neuroimage.2019.01.067. Epub 2019 Jan 30. 